УДК 82.091

DOI: $10.21779 / 2542-0313-2017-32-4-60-66$

\title{
H.M. Мустафаева
}

\section{Азербайджано-турецкие литературные связи в начале XX века}

Азербайджанский университет языков; Азербайджсан, AZ 1055, г. Баку, ул. Рашида Бейбутова, 60; nurlana.gasimli@gmail.com

В статье рассматриваются азербайджано-турецкие литературные связи начала XX века, имеющие длительную историю. Литературно-культурные взаимосвязи являются одним из существенных факторов развития современного мира, влияния на общественную жизнь, на расширение всего спектра человеческого мышления, обогащение мировоззрения человека, его художественных взглядов. Влияние поэтов М.А. Юрдагюля, Т. Фикрета, А. Гамида, Р.М. Акрама и других на азербайджанскую литературную среду, связь писателей А. Гусейнзаде, М. Хади, Г. Джавида, А. Суром, А. Джавада и других с турецкой литературной средой обеспечили взаимное сближение культур двух тюркских народов.

Ключевые слова: начало ХХ века, литературные связи между Азербайджаном и Туриией, литературная среда, новый этап развития литературь.

Актуальность рассматриваемой проблемы обусловлена тем, что литературнокультурные отношения считаются наиболее важным фактором в прогрессивном развитии современного мира на основе взаимоуважения и взаимопонимания. Эти связи играют значительную социальную роль в обществе и благодаря эстетическому и психологическому воздействию, обогащают мышление людей, их мировоззрение. Азербайджано-турецкие литературные отношения имеют долгую историю развития. При рассмотрении истории становления этих двух литературных процессов можно заметить, что последнее столетие отличается своеобразием происходящих литературных событий, их богатым содержанием и многоаспектностью их развития. Исходя из проблематики затрагиваемых вопросов, можно сказать, что в целом литературнокультурные связи прошлого века делятся примерно на следующие этапы:

a) период с начала XX века по 20-е годы этого же века;

б) период, охватывающий 20 -е - середину 80 -х годов XX века;

в) период с 80-х годов XX века по сегодняшний день.

Вместе с тем это деление не ограничивается известными событиями, происходившими в XX веке (Первая мировая война, Октябрьская революция 1917 года). Мы не должны также забывать о последствиях этих событий, отразившихся на всей социальной жизни. Так, литературные процессы, которые мы относим к началу века, фактически начались еще в 80-90-е годы XIX столетия. Связь между этими периодами не прервалась даже после изменения политической власти, в условиях формирования коммунистического режима в 20-е годы. Напротив, она существовала вплоть до 1927-го года. Несомненно, что есть и определенные различия в тех процессах, которые происходили здесь все это время. Именно поэтому есть необходимость в выделении азербайджанотурецких связей, которые стали налаживаться в начале XX века, и определении сущности и основных особенностей их дальнейшего развития. На сегодняшний день интерес к проблематике азербайджано-турецких литературных связей растет, о чем свидетельствует ряд разработок азербайджанских и турецких исследователей $[1 ; 10 ; 11 ; 12 ; 13]$. 
Социальные условия формирования взаимодействия в литературном процессе двух стран. Известно, что начало социально-политических, литературнокультурных процессов, происходивших на территории Азербайджана в начале XX века, было заложено еще во второй половине XIX века. То, что М.Ф. Ахундзаде отправился в Турцию по обмену опытом по замене алфавита и выдвинул, исходя из полученной информации, свой собственный проект (возлагая большие надежды на его реализацию), есть одно из самых решающих и важных событий в контексте этих отношений. Подчеркнем и тот факт, что поездка Г.Б. Зардаби в Стамбул в газету «Экинчи» для заимствования арабской графики (для типографии) явилась одним из факторов, способствовавших партнерству в происходящих литературно-культурных процессах. После закрытия газет «Кашкуль», «Зия», «Зияйи Кафкасия» братьев Унсизаде было естественным их обращение за помощью в Османское государство, поскольку между представителями двух стран уже сформировались близкие литературно-художественные связи и отношения для дальнейших действий.

В конце века панисламистская фобия на Западе привела к поиску турецкими народами общих точек опоры. Джамаладдин Афгани, который объездил практически весь мир, получил имя панисламиста и фактически стал основателем демократического исламского движения. Он хотел создать исламское единство на основе духовного единства народов всех исламских государств и народов. Распространение идеи газеты Исмаила Бея Каспралы «Тарджуман» и его лозунга «единство в языке, в идее, в работе» как общей идеи всех тюрок усилило это сближение.

А.Б. Агаоглу, будучи студентом в Париже, был близок с Афгани и многому у него научился. Когда Агаоглу вернулся на родину, он неоднократно встречался с ним в Стамбуле, что способствовало распространению этих идей и в Азербайджане. Дж. Афгани оказал влияние не только на турецкую литературу, но и на литературнообщественную мысль азербайджанской литературной среды. Ш. Гурбанов так пишет о влиянии Дж. Афгани на развитие общественно-политической мысли всех народов Ближнего Востока: «То, что мы говорим о творчестве таких поэтов, как Мехмет Амин Юрдагюль и Мехмет Акиф Эрсой, связано с тем, что они писали поэмы и стихи о его (Дж. Афгани. - H.M.) связях с «младотюрками» и всегда вспоминали его с благодарностью» [1, с. 5]. По-видимому, в начале века у этих турецких поэтов, находившихся под сильным влиянием идей Дж. Афгани, была также возможность оказать влияние на азербайджанскую литературную среду. Есть сведения о том, что в 1990-х годах, в период пребывания Дж. Афгани в Стамбуле, с его участием проходили собрания многих интеллектуалов. Можно предположить, что среди них были и азербайджанцы, в том числе А. Гусейнзаде, который в то время учился в Стамбуле.

Роль отдельных представителей турецкой литературы в становлении новой литературной среды в Азербайджане. В целом стоит подчеркнуть, что в азербайджанской литературной среде наиболее популярным турецким поэтом считался Мехмет Амин Юрдагюль (1869-1944). В начале XX века его стихи начали публиковаться и в Азербайджане. Особенную популярность получили его зарифмованные марши, что оказало большое влияние на азербайджанских поэтов. Его стихотворение «Голос из Анадолу, или Строй под звуки дженги» (воинственный строй музыки) стало строевой песней и было напечатано в газете «Терегги», издаваемой А.Б. Гусейнзаде:

Я тюрок с древним родом, верой,

И грудь моя, и я отвагою полны.

Коль человек ты, то служи Отчизне,

Наследник тюрка рвется в бой из дома...

Слезы я утру саваном белым, 
Наточу я нож о камень черный,

Родине моей я славы пожелаю,

Никто не вечен в мире этом, знай... [2].

В качестве комментария к стихотворению была напечатана статья «Тюркизм, армия и события 31 марта в Стамбуле». Исследователи обращают внимание на появление подражаний ему, что свидетельствует о сформировавшейся общей литературной среде. К примеру, обращается внимание на то, что Г. Джавид использовал в своей пьесе «Марал» некоторые строки из вышеуказанного произведения [3, с. 24]. Часто к творчеству М.А. Юрдагюля обращались видные азербайджанские поэты Аббас Саххат и Мирза Алекпер Сабир. Так, Г. Гашимли пишет, что «в целом в прошлом веке, точнее в первых десятилетиях, мы можем найти многочисленные подтверждения тому, что творчеству М.А. Юрдагюля уделялось значительное внимание, к примеру, в отдельных хрестоматиях, книгах, на страницах печати. Этот процесс получил новое дыхание в период существования Азербайджанской Демократической Республики в 1918-1920-е годы» [3, с. 27].

Таким образом, в указанный период литературная элита Азербайджана активно обращалась к произведениям турецких поэтов, таких, как М. Юрдагюль, Намик Кемаль, Тофик Фикрет, в особенности в военно-патриотическом воспитании. Стихи публиковались как в отдельных газетах, так и в книгах. К примеру, они были включены в сборник «Армейские марши». Все стихи сыграли важную посредническую роль в налаживании диалога между литературной и культурной средами. В целом патриотические, наполненные национальным духом стихи М. Юрдагюля оказали большое влияние на творчество азербайджанских поэтов (начиная с первых лет XX столетия до 30-х годов): А. Шаига, А. Джавада, А. Абида, Умгюльсум, М. Мушфига, А. Ильдрыма и др.

О деятельности А.Б. Гусейнзаде. Фактором, оказавшим исключительное влияние на формирование литературной среды, общей для двух стран, стало возвращение примерно через пятнадцать лет (в конце XIX века) А.Б. Гусейнзаде из СанктПетербурга где он изучал медицину, в Стамбул, с новыми идеями. Такое же влияние оказало возвращение после обучения из Турции в Азербайджан Омара Фаика Неманзаде, Гусейна Джавида, Абдуллы Сура. Это ускорило сближение представителей литературных сред, их идейное формирование. Г.Б. Зардаби, А.Б. Гусейнзаде, А. Агаоглу, О.Ф. Неманзаде, Г. Джавид, М. Хади, А. Сур и другие также активно участвовали в процессе взаимовлияния литератур двух народов. Если мы посмотрим на характер проблем, которые они ставили в своих произведениях, то нетрудно догадаться, что тематика и проблематика исходят от турецких поэтов и писателей. Более того, многие писатели и журналисты из Турции также пытались повлиять на оживление литературной деятельности интеллигенции в Азербайджане.

Этот процесс ускорился после прибытия А. Гусейнзаде в Баку. Так, с выходом в свет газеты «Хаят» стали усиливаться тенденции исламизма и тюркизма в общественной мысли. На страницах газеты «Хаят» $(1905$, № 4, 9, 16, 22, 35, 52, 81, 82) была опубликована серия статей А. Гусейнзаде на тему «Кто такие тюрки, и из кого они состоят». Статья начиналась следующим высказыванием: «В начале каждого издания нашей газеты упоминается, что тюркский язык и исламиййа внешне кажутся ясными и очевидными. Но правда не так проста. Эти выражения кажутся простыми, легкими, близкими, и все думают, что это не обязательно для объяснения, толкования или интерпретации» [4].

В целом ясно, что с появлением газет «Хаят» и «Фийюзат» в Азербайджане влияние тюркского фактора и турецкой тематики усиливается. В частности, после выхода 
газеты «Фийюзат» турецкая тематика была на страницах этого издания больше представлена. На первых полосах газеты «Фийюзат» был опубликован портрет автора конституционной реформы, принятой в 1874 году в Османской империи. Естественно, что это также оказывало свое влияние на формирование общественного мнения людей, в том числе у представителей литературной среды в Азербайджане. Идея создания общетюркского литературного языка А. Гусейнзаде широко обсуждалась на страницах газеты «Фийюзат». Одним из авторов статей в газете «Фийюзат» был Ахмед Кемаль (1873-1942). Ахмед Кемаль не просто публиковался здесь, он также работал в Баку. Войдя в эту литературную среду, он активно защищал свои позиции.

О литературной деятельности Ахмеда Кемаля. Ахмед Кемаль родился в Стамбуле и получил образование в школе «Дарюш-шафаг», а затем остался здесь учителем. Он также публиковал статьи в газетах Стамбула «Сарвати-Фюнун» и «Сабах». Некоторое время, во время пребывания в Египте, он издавал газету «Правое слово». Но, как оказалось, его критические взгляды как в Турции, так и в Египте были повернуты против него, и ему пришлось покинуть эти страны. В это время А. Гусейнзаде пригласил его в Баку. Здесь А. Кемаль работал в 1906-1911 годах преподавателем и директором в школе «Саадат» и Издательско-просветительской школе в Балаханах. Помимо прочего, он писал стихи.

Здесь был опубликован ряд его статей и стихов. Эти статьи широко использовались в пропаганде национального патриотизма, идей прогресса и тюркизма. Поскольку в газете «Фийюзат» особое значение придавалось сотрудничеству с ним, коллектив подготовил и опубликовал статью «Наш новый товарищ по перу». В статье подчеркивалось, что «формирование новых литературных идей, связанных с новейшими вопросами прогресса и показывающих преданность национальной литературе, связано с именами Тофика Фикрета, г-на Шахебеддина, Исмаила Сафа, А. Надира, Гусейна Сюада, Г. Сифата, Сулеймана Насиба. К сожалению, семь или восемь из вас, отказавшись от военной службы по соображениям совести, были вынуждены отправиться за границу, не выдержав давление оттоманской бюрократии» [5].

Ахмед Кемаль был одним из самых активных турецких авторов в Баку. Поскольку его мысли совпадали с идеями А. Гусейнзаде, он часто выступал на страницах газеты «Фийюзат». После того как это издание было закрыто, он публиковался в других изданиях, в том числе в «Ени Фийюзат». Даже после отъезда А. Гусейнзаде из Баку, он некоторое время оставался там. Его поэтическое творчество широко использовалось в романтическом, философском смыслах в качестве крылатых выражений. Стихотворение «Философская печаль» было одним из его самых обсуждаемых поэтических произведений в бакинской литературной среде:

Мой мозг распался под бременем печали...

Я жемчужина, что вверглась в колесо времени!

При виде этого душа становится загадкой;

Нет веры в друга, во врага, во времена!

Мне называют книгу, я ее учу;

Но чужда книга та, что во мне!.

Вселенная едина, всеохватна,

Едина в сущности своей, в очарованьи!

Вопросы, что пытают о природе,

Ответ свой получают, и мгновенно! [6].

Также необходимо сказать, что во многих случаях язык этого автора, который призывает к прогрессу и развитию, столь же сложен, как и язык А. Гусейнзаде, и из-за этого его часто подвергали критике. Во время работы в Издательско-просветительской 
школе в Балаханах он встречался с великим азербайджанским сатириком Мирзой Алекпер Сабиром. Между ними возникали определенные трения. И. Габиббейли пишет об отношениях между этими двумя поэтами: «Когда Ахмад Кемаль Бей был директором школы в Балаханы, там работал Мирза Алекпер Сабир. Впрочем, между ними были неприятные разногласия. Молланасреддинцы, которые категорически были против такого отношения к М.А. Сабиру, вместе с тем признавали в Ахмаде Кемале Бее опытного учителя, известного писателя и автора легкого пера, ... патриота» [7, с. 437].

О кипрском поэте Ахмеде Раиге. Одним из поэтов, чьим произведениям газета «Фийюзат» на своих страницах уделяла большое внимание, был кипрский поэт Ахмед Раиг (1885-1962). В газете «Фийюзат» было опубликовано много его стихотворений, публицистических работ и переводов. В этих работах он поднимал проблемы солидарности тюркских народов, вопросы организации образования и создания общего литературного языка. Как и у редактора «Фийюзата» А. Гусейнзаде, вопросы чистоты и совершенствования литературного языка были одной из главных проблем в его работах. Его наибольшим вкладом в развитие и совершенствование азербайджанской литературной среды было обогащение поэтического творчества в сфере лирической поэзии.

Лирическое описание событий, гармония и ритмика, а также эмоциональность в его художественном творчестве стали основой для создания новых, оригинальных образцов поэтического жанра. В лирическом стихотворении «Суть родины» с большой художественной выразительностью создан образ лирического героя, живущего тоской по родине. Г. Гашимли, который высоко оценивает творчество поэта вклад его в популярность газеты «Фийюзат», пишет: «Вызывает интерес такая особенность, как то, что А. Раиг проделал определенную работу, чтобы донести до сведения азербайджанских читателей содержание произведений известных турецких поэтов. К примеру, он довел до читателей стихи Тофика Фикрета, причем переложенные на прозу. Можно оценить такие образцы переложения, как «белый стих», в которых выражаются отдельные лирические отрывки» [3, с. 33].

О деятельности Махмуда Акрама Раджаизаде и Абдуллы Джовдета. Следует сказать и о знаменитых произведениях турецких писателей Махмуда Акрама Раджаизаде и Абдуллы Джовдета, опубликованных в Баку. А. Джовдет (1869-1932) был другом А. Гусейнзаде и познакомился с ним еще будучи студентом (они учились вместе). Но затем А. Джовдет отправился в Европу, а А. Гусейнзаде, переехав в Баку, писал ему письма. А. Джовдет, который некоторое время жил в Европе и Африке, переводил произведения Шекспира «Гамлет», Шиллера «Вильгельм Телль», Байрона «Шильонский узник». Также известны его стихи, издательская деятельность и публицистические статьи. Некоторые из его работ были использованы в сборнике «Фийюзат». А. Гусейнзаде уделял большое внимание его творчеству, почему и обратился в «Фийюзате» к своим читателям со статьей «Абдулла Джовдат» $[8$, с. 6].

Стихи М.А. Раджаизаде были очень популярны в Азербайджане. Некоторые его переводы с европейских языков были также опубликованы в «Фийюзате». В Азербайджане написано много подражаний стихам этого выдающегося представителя турецкой романтической поэзии. В ответ на стихотворение «Помяни» М.А. Раджаизаде А. Шайг написал стихотворение с тем же названием. Стихотворение «Помяни» М.А. Раджаизаде было опубликовано в «Фийюзате». В этом романтико-сентиментальном стихотворении поэт описал свои лирические чувства:

Когда, встав, сердце я похоронил,

То оказался в землю погребенным.

Когда ж земля мне рот закрыла,

То страсть ту песнь наполнила мою. 
В ночах одиноких живут воспоминания,

Мечты мои не сбудутся, однако.

Пусть смолкнет разума и милосердия родник,

Представь, любовь моя, мое несчастье,

И помяни меня, хоть с грустью, помяни! [9, с. 6].

В целом поэзия М. Раджаизаде в начале XX века оказала значительное влияние на творчество видных представителей азербайджанского романтизма Г. Джавида, А. Шайга, А. Саххата. Кроме того, его стихи были опубликованы Ф. Агазаде в 1912 году в «Литературном сборнике».

Общие итоги. В первые десятилетия XX века развивались азербайджанотурецкие литературные отношения, поскольку шло активное взаимовлияние. По мере того как в Азербайджане читались стихи турецких поэтов, турецкие поэты изучали произведения азербайджанских поэтов. А. Сур проучился в Стамбуле и вернулся на родину, но он при этом пытался выразить в стихах свои впечатления. Или, к примеру, изображение в стихах Г. Джавида жизни Турции и литературной жизни в Стамбуле было одним из факторов, сближающих литературную среду двух народов. Непродолжительная работа М. Хади в Турции и публикация стихов и статей в разных печатных агентствах также сыграли важную роль в создании общих элементов в литературной среде каждой из стран.

Этот процесс продолжался до 1920 года, а затем вступил в новый этап. Сближение литературной среды в период АДР продолжалось во всех сферах. Даже политическое и военное единство способствовало достижению пика в литературнокультурной жизни. Стихи турецких поэтов широко использовались при написании и исполнении маршей. Частые поездки А. Джавада в Турцию во время Второй мировой войны, помощь беженцам Карса и его стихотворное творчество при этом также повлияли на формирование общих черт в литературном процессе каждой из стран. Публикация сборника «Братская помощь» в период АДР и продолжение здесь турецкой темы может служить образцом сближения литературных сред.

Выводы. Таким образом, в начале XX века литературные отношения между Азербайджаном и Турцией вышли на новый этап, который характеризуется следующим: общественно-политические процессы в мире оказали определенное влияние на литературные и культурные процессы региона и всего мира в целом. Однако эти процессы не могли длиться долго: с развалом Азербайджанской Демократической Республики и установлением здесь коммунистического режима эти литературные отношения стали слабеть, а взаимное сотрудничество постепенно сошло на нет.

\section{Литература} $220 \mathrm{c}$.

1. Курбанов Ш. Джамаладдин Афгани и тюркский мир. - Баку: Азернешр, 1997. -

2. Юрдагюль М.A. Уйду я // Газета «Терегги». - 1909. - № 75.

3. Гашимли Г. Азербайджанская литературная среда и тюркский мир. - Баку: Мутарджим, 2009. - 200 с. № 4 .

4. Гусейнзаде A. Кто такие тюрки и из кого они состоят // Газета «Хаят». - 1905. -

5. Новые товарищи по перу (от редакции) // Фийюзат. - 1907. - № 18.

6. Ахмед Кямал. Философская печаль // Фийюзат. - 1907. - № 17.

7. Габиббейли И. Литературный персонаж и время. - Баку: Элм и Тахсил, 2017. $168 \mathrm{c}$.

8. Абдулла А.Г. Джовдат // Фийюзат. - 1906. - № 4. 
9. Раджаизаде М.Э. Почти памятью // Фийюзат. - 1907. - № 21.

10. Байрамов С. Современные азербайджано-турецкие литературные отношения (основанные на работах 3. Ягуба и М. Аслана). - Баку, 2016. - 125 с.

11. Кязымоглу Ч.Ф. Религиозные мотивы в азербайджано-турецкой литературе. Баку, 2016. - 90 с.

12. Пекташ Умит. Идейно-тематическое разнообразие художественных образцов детской литературы Турции и Азербайджана в начале XX века. - Баку, 2016. - 178 с.

13. Алескерова С. Слог и жанровая система литературы тюркских народов. Баку: АДПУ, 2016. - 345 с.

Поступила в редакциию 12 декабря 2017 г.

UDC 82.091

DOI: $10.21779 / 2542-0313-2017-32-4-60-66$

\section{Azerbaijani-turkish literary ties of the beginning of the $\mathrm{XX}$ century}

\section{N.M. Mustafayeva}

The Azerbaijan University of Languages; Azerbaijan, AZ1055, Baku, Rashid Beibutov st., 60; nurlana.gasimli@gmail.com

The article reviews the Azerbaijani-Turkish long-lasting literary ties of the early twentieth century. It is noted that literary and cultural interrelations are one of the essential factors of the development in the modern world. These relations are reflected not only in the social significance of literature as a cultural and social phenomenon, including its influence on people's lifes through its cultural, aesthetic and psychological aspects, but also in expanding the entire range of human thinking, enriching the outlook of the human being and his/her artistic views. The influence of such poets as M.Y. Yurdagul, T. Fikret, A. Gamid, R.M. Akram and others on the Azerbaijani literary environment, the ties between such writers as A. Huseynzadeh, M. Hadi, G. Javid, A. Sur, A. Javad and others with the Turkish literary environment ensured the mutual rapprochement of the cultures of the two Turkic nations.

Keywords: beginning of the 20th century, literary ties between Azerbaijan and Turkey, the literary environment, a new stage in the development of literature.

Received 12 December, 2017 